\title{
QUALIDADE DE SEMENTES DE MAMONA EM FUNÇÃO DA ÉPOCA DE SEMEADURA E ORDEM DE RACEMO ${ }^{1}$
}

\begin{abstract}
EBERSON DIEDRICH EICHOLZ², SERGIO DELMAR DOS ANJOS E SILVA
RESUMO - Dentro das oleaginosas com potencial para produção de biodiesel, a mamona apresenta bom desenvolvimento e produtividade na região Sul do RS, porém são poucos os estudos relacionados à tecnologia de produção de sementes. Neste sentido, o objetivo deste trabalho foi avaliar a influência da época de semeadura e da ordem dos racemos, na qualidade das sementes das cultivares AL Guarany 2002 e IAC 80. Para tanto, foram implantados experimentos em dois locais, na safra 2006/07, no município de Canguçu. As cultivares foram semeadas em duas épocas (novembro e dezembro). Foram avaliadas as sementes provenientes das diferentes ordens, quanto às qualidades física e fisiológica. $\mathrm{O}$ delineamento experimental foi o de blocos ao acaso com três repetições, em esquema fatorial 2x3 (época x ordem) para cultivar AL Guarany 2002, e esquema fatorial 2x2 (época x ordem) para a cultivar IAC 80 no local Florida e para semeadura de novembro no local Passo do Quilombo. No local Passo do Quilombo foi analisado somente efeito de época na primeira ordem de floração e efeito de ordem de racemo na semeadura de novembro. De acordo com os resultados, a qualidade física das sementes, peso de mil sementes e peso volumétrico, são afetado pela ordem de racemo e época de semeadura; a cultivar AL Guarany 2002 produz sementes com padrão de qualidade fisiológica na semeadura de novembro, independentemente da ordem de racemo e; a cultivar IAC 80 produz sementes com padrão de qualidade fisiológica, na semeadura de novembro, primeira ordem de racemo.
\end{abstract}

Termos para Indexação: Ricinus comunnis L., sementes, qualidade física, qualidade fisiológica

\section{QUALITY OF SEEDS OF CASTOR BEAN IN FUNCTION OF SOWING DATE AND RACEME ORDER}

\begin{abstract}
Within the oil plant with the potential for biodiesel production, the castor bean has good development and productivity in Southern RS - Brazil, but there are few studies related to seed production technology. In this sense, the objective was evaluate the sowing date influence in seed quality of different raceme orders of the AL Guarany 2002 and IAC 80 cultivars. Experiments were carried out in two places (Passo do Quilombo and Florida), in 2006/07 season, in Canguçu country, using IAC 80 and AL Guarany 2002 cultivars, sowed in two different months (November and December). The experimental design was randomized block with three replications in $2 \times 3$ factorial (sowing date $\mathrm{x}$ raceme order) to AL Guarany 2002, and 2x2 factorial (sowing date $\mathrm{x}$ raceme order) to the IAC 80 in Florida and November sowing in Passo do Quilombo. In Passo do Quilombo was analyzed the effect of date sowing in first raceme order and raceme order effect in November sowing. Physiological and physic quality of seeds from different raceme-orders were evaluated. According with results, the seeds physical quality, thousand seed weight and
\end{abstract}

1Submetido em 09/06/2010. Aceito para publicação em 22/10/2010. Parte da Tese de Doutorado do primeiro autor apresentada a FAEM/UFPEL.

${ }^{2}$ Eng. Agrôn. D.sc. Pesquisador da Embrapa Clima Temperado, Pelotas,
RS, eberson.eicholz@cpact.embrapa.br

${ }^{3}$ Eng. Agrôn. D.sc. Pesquisador da Embrapa Clima Temperado, Pelotas, RS, sergio@cpact.embrapa.com 
volumetric seed weight, is affected by the raceme order and sowing date; the cv. AL Guarany 2002 seeds presents higla physiological quality in November sowing, independently of raceme order and cv. IAC 80 seeds have better physiological quality in the November sowing in first order racemes.

Index Terms: Ricinus comunnis L.; seeds; physic quality; physiologic quality.

\section{INTRODUÇÃO}

As demandas em pesquisa por alternativas de renda para meio rural, aliado aos investimentos do Governo Federal para diversificação de oleaginosas para biodiesel, colocam a mamona em destaque, como uma cultura potencial para estes fins. Segundo Silva et al. (2007), a mamona apresentou produtividades representativas com elevado teor de óleo na Região Sul do RS.

Entre outras demandas, a falta de sementes de qualidade é limitante para a expansão da cultura. Por ser de cultivo relativamente recente no Estado, poucos são os resultados de pesquisa sobre a cultura e sobre a produção de sementes.

A importância da época de semeadura e do local de cultivo sobre comportamento e produção de mamona no RS é apresentada por Zuchi et al. (2009), estes fatores condicionam as características morfológicas e o aparecimento de certas pragas e doenças na cultura. Devido ao hábito de crescimento indeterminado, a mamona produz várias ordens de racemo, que ficam expostas a diferentes condições de precipitação, temperatura e fotoperíodo (Kumar et al., 1997) .Estes fatores contribuem certamente para as diferenças nos resultados encontrados para a qualidade de sementes e indicações de uso. Autores como Machado et al. (2009), recomendam para obter sementes de qualidade utilizar os racemos primários e secundários da cultivar AL Guarany 2002. Trabalhos com outras cultivares, como IAC 2028 (Fanan et al., 2009) e Sipeal-1 (Lins et al., 1976), não mostraram diferenças entre as ordem de racemos, e para cultivar Paraibana (Lins et al.,1976) as sementes das ordens secundárias e terciárias são melhores para plantio.

Estes resultados sugerem a influência das características genéticas de cada cultivar, sobre a qualidade das sementes, entre as ordens de racemo, aliado as condições ambientais, refletindo na produtividade, na maturação e na qualidade das sementes. Assim, o objetivo deste trabalho foi estudar a influência da época de semeadura e da ordem de racemo na qualidade física e fisiológica de sementes das cultivares de mamona $\mathrm{AL}$ Guarany 2002 e IAC 80.

\section{MATERIAL E MÉTODOS}

A condução do experimento foi realizada no município de Canguçu, na safra 2006/2007, em dois locais, Florida e Passo do Quilombo. Na localidade de Florida a área é levemente ondulada, estando localizada na latitude $31^{\circ} 12^{\prime} 13^{\prime \prime}$ S, longitude $52^{\circ} 40^{\prime} 08^{\prime}$ 'O e altitude de 300 $\mathrm{m}$. Em Passo do Quilombo o relevo é ondulado, com latitude $31^{\circ} 24^{\prime} 09^{\prime}$ 'S, longitude $52^{\circ} 40^{\prime} 05^{\prime}$ 'O e altitude de $370 \mathrm{~m}$.

Foram utilizadas as cultivares AL Guarany 2002, lançada pelo Departamento de Sementes, Mudas e Matrizes - Coordenadoria de Assistência Técnica Integral (CATI), que apresenta ciclo de 180 dias (até a colheita dos racemos terciários), porte médio e fruto indeiscente (Silva et al., 2007), e a cultivar IAC 80 que foi lançada em 1982 pelo Instituto Agronômico de Campinas/Seção de Oleaginosas, Campinas, SP, a qual apresenta ciclo de 240 dias, porte alto e fruto semideiscente (Savy Filho, 2005).

Utilizou-se o sistema de cultivo convencional com uma aração e duas gradagens precedentes à semeadura. O espaçamento utilizado foi de $1,5 \mathrm{~m}$ entre linhas e 0,80 $\mathrm{m}$ entre plantas, resultando numa população de 8.333 plantas por hectare para cultivar AL Guarany 2002 e espaçamento de 1,5 m entre linhas e 1,6 m entre plantas para cultivar IAC 80, o que possibilitou uma população de 4.167 plantas por hectare. Conforme a análise do solo os dois ambientes possuíam teor de matéria orgânica (baixo), CTC (médio), teor de fósforo (muito baixo), 
potássio (médio), a textura do solo no local Florida era classe quatro e índice SMP $(6,0)$ e no local Passo do Quilombo textura classe três e índice SMP $(5,9)$. A adubação foi realizada conforme recomendação de Silva et al. (2005). A parcela experimental foi constituída de 4 linhas de 16 metros. Foram utilizadas duas épocas de semeadura. A primeira época foi semeada nos dias 02 e 04 de novembro e a segunda época nos dias 02 e 04 de dezembro. A semeadura foi manual utilizando-se duas sementes por cova, permanecendo uma planta após o desbaste, que foi realizado aos 15 dias de emergência. Para as avaliações foram coletadas racemos de diferentes ordens com mais de $95 \%$ dos frutos secos. $\mathrm{Na}$ cultivar AL Guarany 2002 foram coletadas as sementes dos racemos de primeira, segunda e terceira ordem e para cultivar IAC 80 a primeira e a segunda ordem nas plantas do local Florida, para as duas épocas de semeadura. No local Passo do Quilombo, nas plantas da semeadura de novembro os racemos foram colhidos conforme o local Florida, porém nas plantas da semeadura de dezembro, foram colhidos os racemos de primeira e segunda ordem na cultivar AL Guarany 2002 e somente a primeira ordem de racemo da cultivar IAC 80. Os dados de precipitação para cada local foram obtidos em pluviômetros tipo cunha capacidade de 130 $\mathrm{mm}$, instalado em área aberta a um metro do solo e os dados de temperatura máxima e mínima referem-se aos da região obtidos no endereço eletrônico do Instituto Nacional de Meteorologia (INMET). Dessa forma, o delineamento experimental foi o de blocos ao acaso com três repetições, em esquema fatorial 2x3 (época $x$ ordem) para a cultivar AL Guarany 2002, e esquema fatorial $2 \times 2$ (época $\mathrm{x}$ ordem) para a cultivar IAC 80 no local Florida e para semeadura de novembro no local Passo do Quilombo. Para semeadura de dezembro no local Passo do Quilombo o efeito de época para primeira ordem de racemo e efeito de ordem para primeira época, considerando que neste local nas plantas da semeadura de novembro, não ocorreu a produção de sementes nas condições descritas (racemos com 95\% ou mais dos frutos secos) na segunda da cultivar IAC 80 e terceira ordem para AL Guarany 2002. A colheita foi escalonada, realizando-se de uma a duas por ordem de racemo (Figuras 1 e 2). Para reduzir e uniformizar da umidade para facilitar a debulha, os frutos foram levados ao laboratório de secagem e beneficiamento da Embrapa Clima Temperado. A secagem foi realizada em secador estacionário à temperatura de $45^{\circ} \mathrm{C}$ por 48 horas. Para o beneficiamento da semente utilizou-se o descascador de mamona da marca ECIRTEC ${ }^{\circledR}$, modelo DME100, capacidade $100 \mathrm{~kg} \mathrm{~h}^{-1}$ e potência de 2,5cv. O descascador é constituído com discos de borracha especial, montados em rotor. A separação da casca foi feita por coluna de ar de ventilador centrífugo. Foi realizado um revestimento com manta de borracha nas laterais do equipamento, para redução de dano mecânico.Após a limpeza as sementes foram levadas ao Laboratório de Análise de Sementes da Embrapa Clima Temperado onde foram armazenadas em câmara seca até a realização dos testes: peso de mil sementes (PMS), conforme as Regras para Análise de Sementes - RAS (Brasil, 1992); peso volumétrico (PV), determinado pelo uso do teste da "canequinha" (Baudet e Peske, 2004), com duas repetições por amostra. Para determinação, foi usado um recipiente de $150 \mathrm{~mL}$, onde foram despejadas sementes a altura de $10 \mathrm{~cm}$ acima da borda do recipiente, enchendo-o e retirando o excesso com régua. A amostra foi pesada em balança analítica com precisão de 0,01 gramas e os resultados foram transformados para $\mathrm{kg} \mathrm{m}^{-3}$. O Teste de Germinação (TG) foi conduzido em rolo de papel, temperatura de $25{ }^{\circ} \mathrm{C}$, duas contagens sete e 14 após semeadura, conforme as Regras para Análise de Sementes - RAS (Brasil, 1992). Os testes Primeira Contagem do Teste de Germinação (PCTG) e Classificação do Vigor de Plântulas (CVP) foram conduzidos conjuntamente com o teste de germinação, seguindo a metodologia de Krzyzanowski et al. (1999). Os testes de Emergência de plântulas em Solo (ES) foram realizados na casa de vegetação, em bandejas de isopor com 72 células. Foi utilizado o substrato PLANTMAX ${ }^{\circledR}$ e solo autoclavado em proporção de $1: 1 \mathrm{v} / \mathrm{v}$. A irrigação foi realizada duas vezes ao dia com regador manual de crivo fino. A temperatura interna na casa de vegetação oscilou entre 20 e $35{ }^{\circ} \mathrm{C}$. A unidade experimental foi constituída de duas unidades de observação, compostas de 50 sementes e 6 repetições, seguindo o delineamento do campo. A contagem das plântulas foi realizada 14 dias após a semeadura e a verificação do índice de velocidade de emergência (IVE) foi realizada conjuntamente com o teste de emergência de plântulas em solo, segundo metodologia de Maguire (1962), sendo a contagem feita até o $14^{\circ}$ dia da semeadura. Os dados foram submetidos à análise de variância e as médias foram comparadas pelo teste $F(\alpha=0,05)$ quando o fator apresentava dois níveis e pelo teste de Duncan $(\alpha=0,05)$ quando apresentava três. 


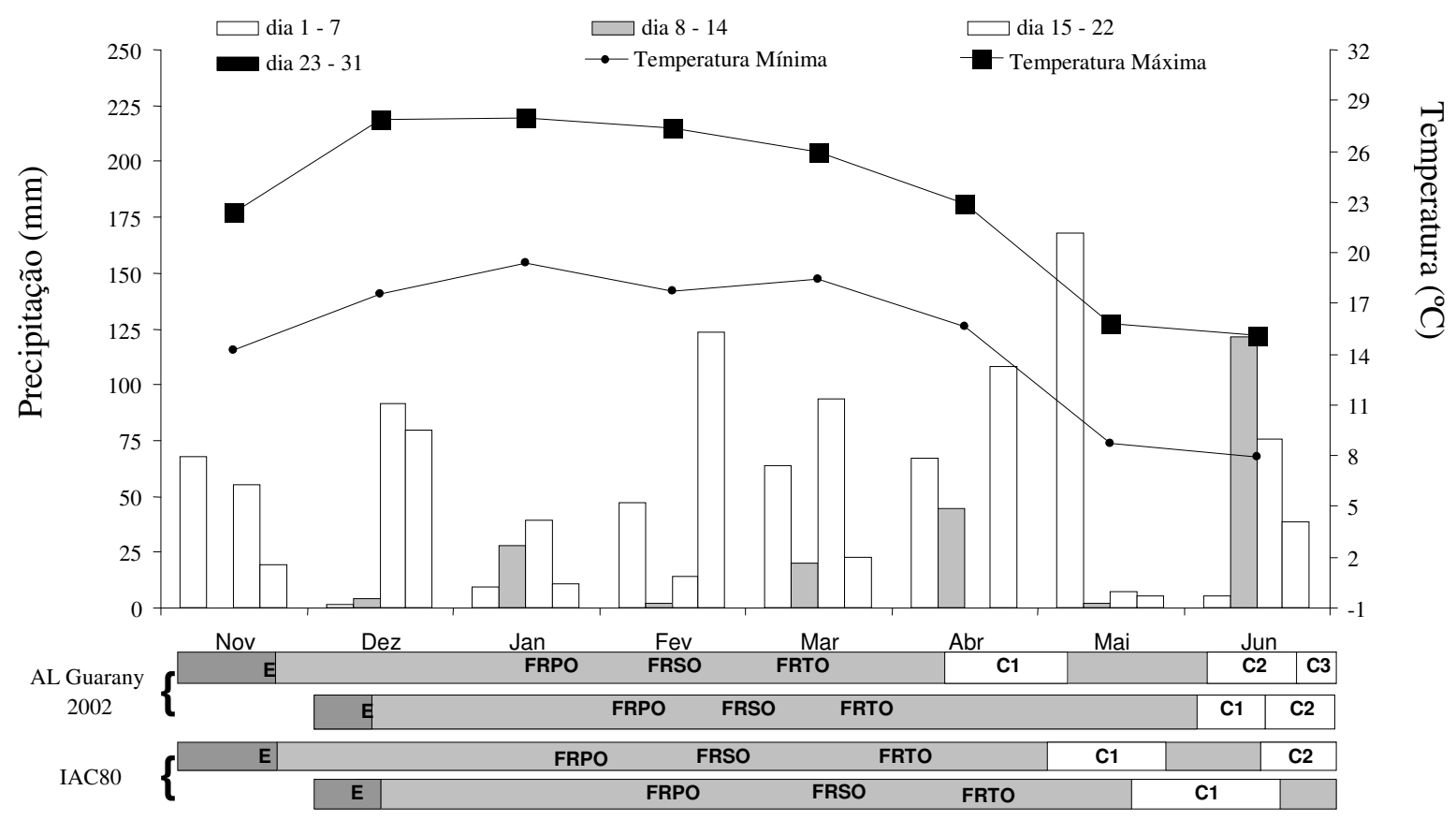

FIGURA 1. Dados de precipitação $(\mathrm{mm})$, médias da temperatura $\left({ }^{\circ} \mathrm{C}\right)$ e estágios fenológicos das cultivares de mamona AL Guarany 2002 e IAC 80, no local Passo do Quilombo, safra 2006/07.

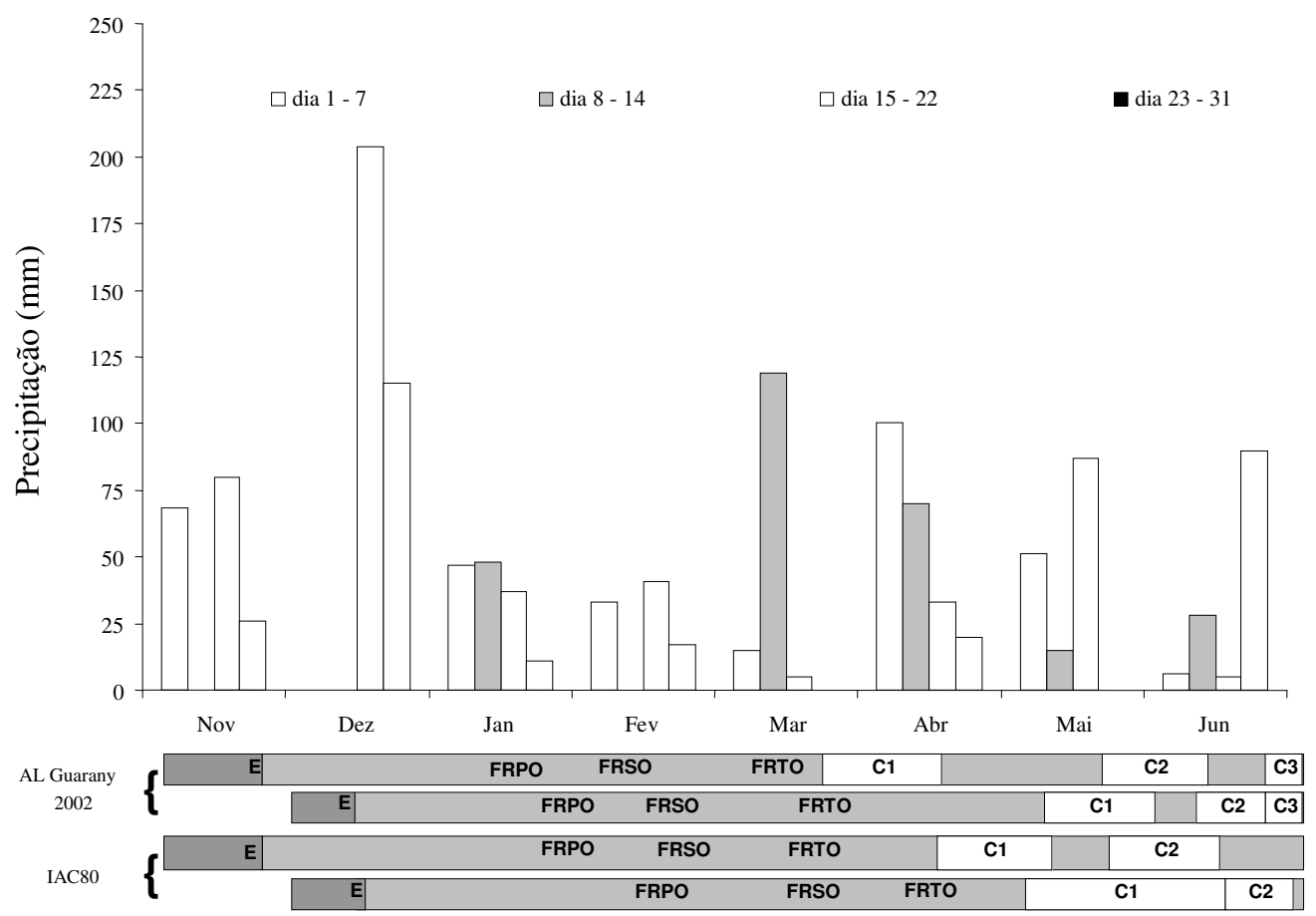

FIGURA 2. Dados de precipitação ( $\mathrm{mm})$ e estádios fenológicos das cultivares de mamona AL Guarany 2002 e IAC 80, no local Florida, safra 2006/07.

E - emergência; FRPO - Floração racemo $1^{\mathrm{a}}$ ordem; FRSO - Floração racemo $2^{\mathrm{a}}$ ordem; FRTO - Floração racemo $3^{\mathrm{a}}$ ordem; C1 - colheita dos racemos $1^{\mathrm{a}}$ ordem; C2 - colheita dos racemos de $2^{\mathrm{a}}$ ordem e C3 - Colheita do racemo de $3^{\mathrm{a}}$ ordem. 


\section{RESULTADOS E DISCUSSÃO}

Para facilitar a compreensão dos resultados foram apresentados os quadros da análise de variância indicando as médias e as interações para cada cultivar e local. Cultivar AL Guarany 2002 (Tabela 1) e cultivar IAC 80 (Tabela 3).

Para cultivar AL Guarany 2002 no local Passo do Quilombo, as sementes das plantas semeadas em novembro foram mais leves na segunda ordem de racemo, ao passo que, na de dezembro, não apresentou diferenças entre as ordens (Tabela 2). Comparando épocas para esta variável verificou-se que na primeira ordem as sementes da semeadura de novembro foram mais pesadas. No local Florida as sementes da primeira ordem apresentaram maior PMS, e na comparação entre épocas, às sementes das plantas da semeadura de dezembro foram as mais pesadas, o mesmo foi observado, na cultivar IAC 80 no local Florida (Tabela 4). É provável que os resultados deste teste, estejam relacionados com as condições ambientais no período de formação e enchimento das sementes, corroborando com Zuchi et al. (2010), quando diz que as condições ambientais como longos períodos de estiagem, durante o desenvolvimento e maturação das sementes de mamona, podem afetar o peso de mil sementes dessa planta. Provavelmente estas condições de clima sejam os responsáveis pelos diferentes resultados com relação ao peso das sementes e ordem de racemo encontrado na literatura, onde para autores como Machado et al. (2009), em valores médios, o racemo primário produziu sementes mais pesadas que os demais, já Lins et al. (1976) e Souza et al. (2006) verificaram sementes mais pesadas nos racemos secundários e terciários e ainda outros como Banzato e Rocha (1965) concluíram que ocorre redução do peso das sementes com o aumento na ordem de floração.

TABELA 1. Resumo da análise de variância, decomposição da interação, indicando graus de liberdade (GL) e os quadrados médios das variáveis resposta para cv. AL Guarany 2002.

\begin{tabular}{|c|c|c|c|c|c|c|c|c|c|c|c|c|c|c|c|c|c|}
\hline \multicolumn{18}{|c|}{ Local Passo do Quilombo } \\
\hline Fonte & GL & PMS & & PV & & TG & & $\mathrm{SD}$ & & PCG & & CVP & & $\mathrm{ES}$ & & IVE & \\
\hline Época (E) & 1 & 466 & $*$ & 154 & & 352 & $*$ & 520 & $*$ & 176 & $*$ & 261 & $*$ & 52 & & 0,12 & \\
\hline Ordem $(\mathrm{O})$ & 2 & 396 & $*$ & 22 & & 128 & $*$ & 145 & $*$ & 122 & $*$ & 107 & $*$ & 67 & $*$ & 0,51 & $*$ \\
\hline bloco & 2 & 154 & $*$ & 67 & & 1,3 & & 2,5 & & 106 & $*$ & 61 & & 18 & & 0,17 & \\
\hline $\mathrm{E}^{*} \mathrm{O}$ & 1 & 464 & $*$ & 574 & $*$ & 271 & $*$ & 200 & $*$ & 85 & $*$ & 48 & & 102 & $*$ & 0,65 & $*$ \\
\hline Média & & 456 & & 555 & & 81 & & 14 & & 65 & & 70 & & 91 & & 5,38 & \\
\hline Erro & 8 & 26 & & 48 & & 2,4 & & 15 & & 11 & & 21 & & 12 & & 0,05 & \\
\hline CV (\%) & & 1,1 & & 1,3 & & 1,9 & & 27,8 & & 5,1 & & 6,5 & & 3,8 & & 4,1 & \\
\hline \multicolumn{18}{|c|}{ Local Florida } \\
\hline Fonte & GL & PMS & & PV & & TG & & $\mathrm{SD}$ & & PCG & & CVP & & ES & & IVE & \\
\hline Época (E) & 1 & 5033 & $*$ & 672 & & 35 & & 9 & & 0,2 & & 4,5 & & 41 & & 0,33 & \\
\hline Ordem $(\mathrm{O})$ & 2 & 844 & $*$ & 1201 & $*$ & 44 & $*$ & 199 & & 158 & $*$ & 22 & & 34 & & 0,34 & \\
\hline bloco & 2 & 135 & & 138 & & 6 & & 11 & & 27 & & 9 & & 10 & & 0,17 & * \\
\hline $\mathrm{E}^{*} \mathrm{O}$ & 2 & 201 & & 57 & & 62 & $*$ & 80 & & 74 & & 46 & & 8 & & 0,17 & \\
\hline Média & & 445 & & 551 & & 80 & & 16 & & 68 & & 72 & & 91 & & 5,36 & \\
\hline Erro & 10 & 147 & & 158 & & 8 & & 7 & & 27 & & 17 & & 4,6 & & 0,03 & \\
\hline $\mathrm{CV}(\%)$ & & 2,7 & & 2,3 & & 3,5 & & 16,7 & & 7,7 & & 5,7 & & 2,4 & & 3,4 & \\
\hline
\end{tabular}

* significativo pelo teste de $\mathrm{F}(\alpha=0,05)$. 
TABELA 2. Peso de mil sementes (PMS), peso volumétrico (PV), teste de germinação (TG), Semente duras (SD) primeira contagem do teste de germinação (PCTG), classificação do vigor de plântulas (CVP), emergência de plântulas em solo (ES) e índice de velocidade de emergência (IVE) de sementes de mamona da cultivar AL Guarany 2002, por local, época de semeadura e ordem de racemo - safra 2006/07.

\begin{tabular}{|c|c|c|c|c|c|c|c|c|c|}
\hline Local & Época & Racemo & PMS* ** & $\mathrm{PV} * * *$ & $\mathrm{TG} * * *$ & $\mathrm{SD} * * *$ & PCTG*** & $\mathrm{EC} * * *$ & IVE**** \\
\hline \multirow{6}{*}{$\begin{array}{l}\text { Passo do } \\
\text { Quilombo }\end{array}$} & & Ordem 1 & 475 a $\mathrm{A}$ & $551 \mathrm{~b} \mathrm{~A}$ & 84 a A & 8 a A & $63 \mathrm{~b} \mathrm{~A}$ & 92 a A & 5,27 b A \\
\hline & Nov & Ordem 2 & 448 b A & 566 a A & 85 a $A$ & 9 a B & $68 \mathrm{ab} A$ & 92 a A & 5,41 b A \\
\hline & & Ordem 3 & 469 a & $554 \mathrm{ab}$ & 86 a & 8 a & $77 \mathrm{ab}$ & 96 a & 5,93 a \\
\hline & & Ordem 1 & 450 a B & 558 a A & 83 a $A$ & $13 \mathrm{~b} \mathrm{~A}$ & 61 a A & 94 a A & 5,53 a $A$ \\
\hline & Dez & Ordem 2 & 447 a A & 545 a B & 64 b B & 30 a $\mathrm{A}$ & 55 a B & $82 \mathrm{~b} \mathrm{~A}$ & 4,74 b A \\
\hline & & Ordem 3 & - & - & - & - & - & - & $-\quad-$ \\
\hline \multirow{11}{*}{ Florida } & & Ordem 1 & & & 81 a $A$ & $11 \mathrm{~b} \mathrm{~A}$ & & & 4,99 b B \\
\hline & Nov & Ordem 2 & & & 76 a B & 19 a A & & & 5,62 a $A$ \\
\hline & & Ordem 3 & & & 78 a A & 20 a A & & & 5,06 b A \\
\hline & & Ordem 1 & & & 82 a A & $12 \mathrm{~b} \mathrm{~A}$ & & & 5,64 a $A$ \\
\hline & Dez & Ordem 2 & & & 86 a A & 9 b A & & & 5,61 a $A$ \\
\hline & & Ordem 3 & & & 75 b A & 24 a A & & & 5,23 a $A$ \\
\hline & & Ordem 1 & 459 a & $539 \mathrm{~b}$ & & & $62 \mathrm{~b}$ & $90 \mathrm{~b}$ & \\
\hline & & Ordem 2 & $438 \mathrm{~b}$ & 566 a & & & $70 \mathrm{a}$ & 94 a & \\
\hline & & Ordem 3 & $439 \mathrm{~b}$ & $547 \mathrm{~b}$ & & & $72 \mathrm{a}$ & $90 \mathrm{~b}$ & \\
\hline & Nov & & $429 \mathrm{~b}$ & & & & & $90 \mathrm{a}$ & \\
\hline & Dez & & $462 \mathrm{a}$ & & & & & $93 \mathrm{~b}$ & \\
\hline
\end{tabular}

*Médias seguidas de mesma letra minúscula, na coluna, não diferem entre si pelo teste de Duncan $(\alpha=0,05)$.

**Médias seguidas de mesma letra maiúscula, na coluna, não diferem entre si pelo teste $\mathrm{F}(\alpha=0,05)$. 
TABELA 3. Resumo da análise de variância, decomposição da interação, indicando graus de liberdade (GL) e os quadrados médios das variáveis resposta para a cv. IAC 80.

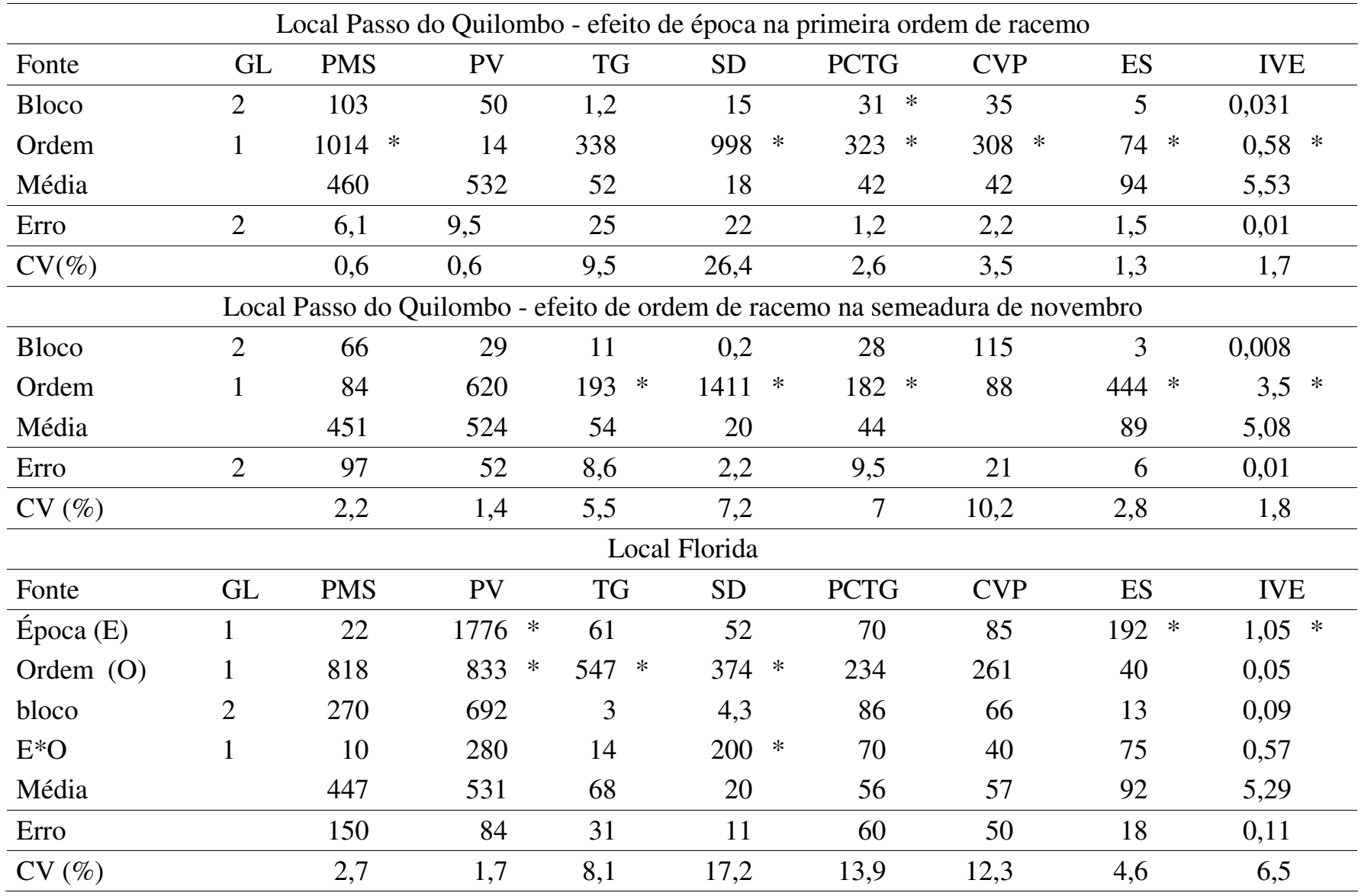

* significativo pelo teste de $\mathrm{F}(\alpha=0,05)$.

TABELA 4. Peso de mil sementes (PMS), peso volumétrico (PV), teste de germinação (TG), Semente duras (SD) primeira contagem do teste de germinação (PCTG), classificação do vigor de plântulas (CVP), emergência de plântulas em solo (ES) e índice de velocidade de emergência (IVE) de sementes de mamona da cultivar IAC 80, por local, época de semeadura e ordem de racemo - safra 2006/07.

\begin{tabular}{|c|c|c|c|c|c|c|c|c|c|}
\hline Local & Fator & PMS* & PV* & $\mathrm{TG}^{*}$ & $\mathrm{SD}^{*}$ & PCTG* & CVP* & ES* & IVE* $^{*}$ \\
\hline \multirow{4}{*}{$\begin{array}{l}\text { Passo do } \\
\text { Quilombo }\end{array}$} & POR & & & 59 a & $5 \mathrm{~b}$ & 49 a & & $97 \mathrm{a}$ & 5,84 a \\
\hline & SOR & & & $48 \mathrm{~b}$ & $35 \mathrm{a}$ & $38 \mathrm{~b}$ & & $80 \mathrm{~b}$ & $4,31 \mathrm{~b}$ \\
\hline & Nov & $447 \mathrm{~b}$ & & & $5 \mathrm{~b}$ & 49 a & 49 a & $97 \mathrm{a}$ & 5,85 a \\
\hline & Dez & 473 a & & & $31 \mathrm{a}$ & $35 \mathrm{~b}$ & $35 \mathrm{~b}$ & $90 \mathrm{~b}$ & $5,22 \mathrm{~b}$ \\
\hline \multirow{4}{*}{ Florida } & POR & & $523 \mathrm{~b}$ & 75 a & & & & & \\
\hline & SOR & & 539 a & $61 \mathrm{~b}$ & & & & & \\
\hline & Nov & & 543 a & & & & & 96 a & 5,58 a \\
\hline & Dez & & $519 \mathrm{~b}$ & & & & & $80 \mathrm{~b}$ & $4,49 \mathrm{~b}$ \\
\hline
\end{tabular}

Médias seguidas de mesma letra minúscula, na coluna, não diferem entre si pelo teste $\mathrm{F}(\alpha=0,05)$.

POR - Primeira Ordem de Racemo; SOR - Segunda Ordem de Racemo; Nov - novembro; Dez - dezembro 
Para peso volumétrico, no local Florida, cultivar AL Guarany 2002 (Tabela 2) observa-se diferenças na semeadura de novembro, superior na segunda ordem, porém, a terceira ordem não diferiu da primeira no local Florida, o que pode estar relacionado com o tamanho ou o enchimento das sementes. No mesmo local esta variável não apresentou diferenças na cultivar IAC 80. No local Florida a segunda ordem de racemo apresentou o maior peso por volume para as duas cultivares testadas, o que pode estar relacionado com o menor tamanho das sementes, visto que estas não diferiram da primeira ordem possuem menor PMS (AL Guarany 2002) ou não diferiram para PMS (IAC 80). E a primeira época de semeadura apresentou as sementes mais pesadas, possivelmente pelo maior período e melhores condições ambientas para enchimento das sementes.

Os atributos físicos avaliados (peso de mil sementes e peso volumétrico) sofreram influência dos fatores época de semeadura e ordem de racemo. E observa-se uma relação inversa em vários tratamentos, o que pode estar relacionado ao tamanho das sementes. O peso médio de mil sementes para as duas cultivares avaliadas ficou em torno de 450 g, porém o peso volumétrico médio foi de $550 \mathrm{~kg} \mathrm{~m}^{-3}$ para cultivar AL Guarany 2002 e $530 \mathrm{~kg} \mathrm{~m}^{-3}$ para cultivar IAC 80, esta diferença possivelmente está relacionado ao formato mais achatado das sementes da cultivar IAC 80 (Tabelas 1 e 3). Segundo Peske e Barros (2003), o peso volumétrico pode ser influenciado pelo tamanho, formato, densidade e grau de umidade nas sementes. Sem variar as outras características, quanto menor for a semente, maior será seu peso volumétrico.

$\mathrm{Na}$ avaliação da qualidade fisiológica das sementes, para a cultivar AL Guarany 2002 semeada em novembro, foi observado que não houve diferenças de germinação das sementes, entre as ordens de racemo (Tabela 2). Entretanto, na semeadura de dezembro as últimas ordens de racemo colhidas produziram sementes com menor porcentagem de germinação, independentemente do local, possivelmente está relacionado, às condições climáticas no momento da maturação e colheita. Mas, independentemente de local ou época, as sementes do racemo primário tiveram mais de $80 \%$ de germinação. Com relação à porcentagem de sementes duras, no local Passo do Quilombo, para a cultivar AL Guarany 2002, não houve diferenças entre ordens de racemo nas sementes provenientes da semeadura de novembro. No local Florida a primeira ordem apresentou o menor valor (11\%) diferindo das demais ordens (19 e 20\%).
Comparando as sementes quanto à época de semeadura verificou-se diferença significativa na segunda ordem de racemo em favor da de dezembro. Comportamento semelhante foi observado nas sementes da terceira ordem no local Florida, o que pode ser resultado de uma indução a dormência das sementes ocasionadas pela redução da temperatura e fotoperiodo (Tabela 2 e Figuras 1 e 2). Para a mesma a cultivar IAC 80 (Tabela 4) observou-se que a segunda ordem de racemos detém maior porcentagem de sementes duras, como observado para cultivar AL Guarany 2002, bem como na comparação entre épocas, a segunda ordem de racemo possuiu a maior porcentagem de sementes duras. Indicando a que quanto mais tardia a semeadura e emissão dos racemos maior a porcentagem de sementes duras. Os resultados deste experimento corroboram com os de Zuchi et al. (2009) e Lago et al. (1979), sugerindo que as sementes de mamona possuem algum tipo de dormência depois de colhidas, com grau variável entre cultivares e ordens de racemo. Para Tillmann et al. (2003), as sementes duras são sementes não germinadas que permaneceram firmes e sem absorver água até o final do teste de germinação. Este fenômeno é motivado pela impermeabilidade do tegumento das sementes à água, sendo considerado um tipo especial de dormência que ocorre em determinadas espécies. Zuchi et al. (2009) observaram que a colheita de frutos de mamona com 100\% dos frutos secos pode induzir dormência nas sementes, porem neste experimento, parece estar relacionado com as condições do clima no momento da colheita das sementes. Com relação a primeira contagem do teste de germinação, os maiores valores estão na segunda e terceira ordem de racemo, exceto para o local Passo do Quilombo. Já para segunda ordem de racemo na semeadura de dezembro, o valor o PCTG foi inferior (Tabela 2).

No teste de classificação do vigor das plântulas observa-se que no local Passo do Quilombo a semeadura de dezembro teve qualidade inferior. Entre ordens a primeira (71\%) e segunda (64\%) apresentou PCTG menor que a terceira ordem de racemo (79\%). E no local Florida não se observaram diferenças quanto a ordem e época de semeadura.

A emergência de plântulas em solo, na casa de vegetação, no local Passo do Quilombo (Tabela 2). mostrou diferenças entre ordens de racemo na semeadura de dezembro, já no local Florida a emergência das plântulas foi superior aos $90 \%$ com variações dependendo da época e ordem de racemo. Para a variável índice de velocidade 
de emergência (IVE), observou-se que a qualidade das sementes, entre as ordens de racemo, depende do local e da época de semeadura mostrando um comportamento distinto entre ordens para cada época e local (Tabela 2).

De forma geral, para cultivar AL Guarany 2002, observou-se que a qualidade fisiológica e vigor variaram com a época de semeadura e ordem de racemo, com comportamento distinto em cada local, estes resultados possivelmente estão relacionados às condições climáticas no momento maturação e colheita das sementes (Figuras 1 e 2). Isso porque o hábito de crescimento da mamona é indeterminado, produzindo várias ordens de racemo, as quais ficam expostas a diferentes condições de precipitação, temperatura e fotoperíodo (Kumar et al., 1997) e podem atingir a maturação em épocas diferentes (Banzatto e Rocha, 1965). Em estudos de Andreuccetti e Sawazaki (1982) com sorgo verificaram que a condição ambiental que ocorreu após a maturação até a colheita foi o que mais contribuiu para diferenciar os locais quanto à germinação e ao vigor das sementes.

Observa-se também que na semeadura de dezembro a segunda ordem possui qualidade fisiológica inferior nos testes de germinação e vigor (EC e IVE) no local Passo do Quilombo, o que não se verificou no local Florida. Isso sugere que ocorreu retardo, também observado nas Figuras 1 e 2 no desenvolvimento das plantas no local Passo do Quilombo possivelmente efeito relacionado ao solo ou clima do local.

Analisando os resultados da cultivar IAC 80 na Tabela 4, verificou-se que, embora não se tenha observado no local Passo do Quilombo diferenças no TG, os testes de vigor PCTG, CVP, ES e IVE mostraram melhor qualidade das sementes oriundas da semeadura de novembro. O mesmo ocorreu com o fator ordem de racemo, onde a primeira ordem de racemo apresentou melhor qualidade inclusive pelo teste de germinação. Isto indica que, para esse cultivar, há uma tendência da semeadura mais tardia reduzir a qualidade de sementes de mamona, o que pode estar relacionado ao maior ciclo da cultivar e a característica de semi-deiscência, visto que ocorreram condições menos favoráveis no final do ciclo, como fotoperíodo menor, temperaturas mais amenas e umidade mais alta, (Figuras 1 e 2) refletindo num aumento das doenças nas sementes.

As sementes de mamona tiveram melhores resultados de emergência de plântulas no solo, quando comparados ao teste de germinação em papel. Este resultado pode estar relacionado à alta percentagem de sementes duras, nos testes em laboratório entre papel.

Considerando as sementes germinadas normais no teste em laboratório, somado às sementes duras, obtêm-se valores acima de $90 \%$, que corresponderiam aos resultados próximos da emergência de plântulas em solo. Sugere-se como possíveis causas deste resultado a contaminação das sementes por fungos (Lima et al., 1997; Mariotto et al., 1987) que com o cultivo em solo poderia, através de controle natural, reduzir o efeito deletério destes; a dormência nas sementes (Lago et al., 1979; Zuchi et al., 2009) que pode apresentar grau variável entre cultivares e ordens de racemo; ou aspectos relacionados à oscilação e picos de temperatura ocorridos na casa de vegetação (Carneiro e Pires, 1983). Neste sentido, existe a necessidade de estudos relacionados aos testes de germinação e vigor (PCTG e CVP) para sementes de mamona. Como também dos patógenos associados as sementes de mamona. Para cultivar IAC 80, a baixa germinação das sementes (inferior aos $70 \%$ ), pode estar relacionada a fatores genéticos, um deles pode ser a característica de semi-deiscência (Savy Filho, 2005), resultando numa maior contaminação das sementes a campo, podendo influenciar na qualidade fisiológica da semente. Com base nestes dados, tem-se forte indicação que os testes de germinação, primeira contagem do teste de germinação e classificação do vigor de plantas quando realizados entre papel, aos $25^{\circ} \mathrm{C}$ não são adequados, em consequência do elevado número de sementes duras.

\section{CONCLUSÕES}

A qualidade física das sementes, o peso de mil sementes e o peso volumétrico, são afetados pela ordem de racemo e época de semeadura.

A cultivar AL Guarany 2002 produz sementes com padrão de qualidade fisiológica e vigor na semeadura de novembro, independentemente da ordem de racemo;

A cultivar IAC 80 produz sementes com padrão de qualidade fisiológica, na semeadura de novembro, na primeira ordem de racemo.

\section{REFERÊNCIAS}

ANDREUCCETTI, J.M. SAWAZAKI, E. Fatores que afetam a qualidade de sementes de sorgo: cultivares e localidades. Bragantia, v.41, n.10, p.101-107, 1982. http:// www.scielo.br/pdf/brag/v41n1/10.pdf .

BANZATTO, N.V.; ROCHA, J.L.V. Florescimento e maturação das cultivares de mamoneira "IAC 
38" e “Campinas". Bragantia, v.24, p.29-31, $1965 . \quad$ http://www.scielo.br/scielo.php?pid=S0006$87051965000100044 \&$ script=sci_arttext

BAUDET, L. L.; PESKE, S. T. Controle interno de qualidade. In: Módulo 9.Brasília, DF: ABEAS - Curso de Especialização em Ciência e Tecnologia de Sementes por Tutoria a Distancia. 50p. 2004.

BRASIL. Ministério da Agricultura e Reforma Agrária. Secretaria Nacional de Defesa Agropecuária. Departamento Nacional de Produção Vegetal. Coordenação de Laboratório Vegetal. Regras para Análise de Sementes. Brasília, DF, 1992. 365p.

CARNEIRO J.W.P.; PIRES J.C. Influência da temperatura e do substrato na germinação de sementes de mamona. Revista Brasileira de Sementes, v.5 n.3, p.127-131. 1983.

FANAN, S.; MEDINA, P.F.; CAMARGO, M.B.P. de; RAMOS; N.P. Influência da colheita e do armazenamento na qualidade fisiológica de sementes de mamona. Revista Brasileira de Sementes, v.31, n.1, p.150-159, 2009. http:// www.scielo.br/pdf/rbs/v31n1/a17v31n1.pdf

KRZYZANOWSKI, F.C.; VIEIRA, R.D.; FRANÇA NETO, J.B. Vigor de sementes: conceitos e testes. Londrina: ABRATES, 1999. 218 p.

KUMAR, P.V. et al. Influence of moisture, thermal and photoperiodic regimes on the productivity of castor beans (Ricinus communis L.). Agricultural and Forest Meteorology, v.88, n.4, p.279-289, 1997.

LAGO, A.A.; ZINKE, E.; RAZERA, L.F.; BANZATTO, N.V.; SAVY FILHO, A. Dormência em sementes de três cultivares de mamona. Brangantia, v.38, p.41-44, 1979. http://www.scielo.br/pdf/brag/v38n1/33.pdf

LIMA, E.F.; BATISTA, F.A.S.; SANTOS, J.W. dos S. Fungos causadores de tombamento transportados e transmitidos pela semente da mamoneira. Pesquisa Agropecuária Brasileira. v.32, n.9. p.915-918. 1997. http://webnotes.sct.embrapa.br/pab/pab.nsf/dfe523788c4d 9ae503256508004f34ca/3a6b8b407f527e190325650d004 $41 \mathrm{fec}$ ? OpenDocument

LINS, E.C.; TÁVORA, F.J.F.; ALVES, J.F. Efeito da ordem do racemo nas características de sementes de mamona (Ricinus communis L.). Revista Ciências Agronômicas, v.6, p.91-98, 1976.

MACHADO, C.G.; MARTINS, C.C.; SILVA L.B. DA; CRUZ, S.C.S. Produção e características físicas de sementes de mamoneira em função da posição do racemo e do fruto. Acta Scientiarum. v.31, n.2, p.293-299, 2009.
http://periodicos.uem.br/ojs/index.php/ActaSciAgron/ article/view/7038/7038

MAGUIRE, J.D. Speed of germination-aid in selection and evaluation for seedlig emergence and vigor. Crop Science, v.2, n.1, p.176-177, 1962.

MARIOTTO, P. R.; BARROS, B. C.; SUGIMORI, M. H.; MENTEN, J. O. M.; MORAES, S. A.; SAVYFILHO, A. Efeito do tratamento químico de sementes de mamona (Ricinus communis L.) avaliado por diferentes métodos de patologia de sementes. Arquivos do Instituto Biológico, São Paulo, v. 54, n. 1-4, p. 37-44, 1987.

PESKE, S.T. \& BARROS, A.C.S.A. Produção de Sementes. In: Sementes: fundamentos científicos e tecnológicos. Pelotas: Universidade Federal de Pelotas. Ed. Universitária, 2003.

SAVY FILHO, A. Mamona tecnologia agrícola. Campinas: EMOPI, 2005. 105p.

SILVA, S.D. dos A.; CASAGRANDE JUNIOR, J.G.; SCIVITTARO, W.B. A cultura da mamona no Rio Grande do Sul. Pelotas: Embrapa Clima Temperado, 2007. 115p. (Embrapa Clima Temperado. Sistemas de produção, 11). http://sistemasdeproducao.cnptia.embrapa. br/FontesHTML/Mamona/SistemaProducaoMamona/ index.htm

SILVA, S.D. dos A.e.; ANDRES, A,; UENO, B.; FLORES, C.A.; GOMES, C.B.; PILLON, C.N.; ANTHONISEN, D.; MACHADO, E.B.; THEISEN. G.; MAGANANI, M.; WREGE, M.S.; AIRES, R.F. A cultura da mamona na região de clima temperado: informações preliminares. Pelotas: Embrapa Clima Temperado, 2005. 56p. (Embrapa Clima Temperado. Documentos, 149).

SOUZA A. dos S.; TÁVORA F.J.A. F. Manejo de plantio e ordem do racemo no teor de óleo e massa de sementes da mamoneira. In: CONGRESSO BRASILEIRO DE MAMONA, 2., 2006, Aracajú. Cenário atual e perspectivas: Anais... Campina Grande: Embrapa Algodão, 2006. 1 CDROM. http://www.cnpa.embrapa.br/produtos/mamona/ publicacoes/trabalhos_cbm2/076.pdf

TILLMANN, M. A. A; MELLO, V. D. C; ROTA, G. R. M. Análise de Sementes. In: Sementes: fundamentos científicos e tecnológicos. PESKE, S. T.; LUCCA FILHO, O. A.; BARROS, A. C. S. A. 2 ed. ver. e ampl. Pelotas: Ed. Universitária/UFPel, p.140-224, 2006.

ZUCHI, J.; PESKE, S.T.; BEVILAQUA, G.A.P.; SILVA, S.D.DOSA.E.Retardamentodecolheita, métododesecagem e qualidade de sementes de mamona. Revista Brasileira de Sementes, v.31, n.3, p.9-15, 2009.http://www.scielo.br/ 
scielo.php?pid=S0101-31222009000300001\&script=sci arttext

ZUCHI, J.; ZANUNCIO, J.C.; BEVILAQUA, G.A.P.; PESKE, S.T.; SILVA, S.D. DOS A.E. Componentes do rendimento de mamona segundo a ordem floral e época de semeadura no Rio Grande do Sul. Revista Ciência Agronômica, v.41, n.3, p.380-386, 2010. http://www. ccarevista.ufc.br/seer/index.php/ccarevista/article/ viewFile/427/455 